\title{
Rhododendron Uses and Distribution of this Knowledge within Ethnic Groups in Northwest Yunnan Province, China
}

\author{
Elizabeth Georgian ${ }^{1,2}$, Eve Emshwiller ${ }^{1}$ \\ ${ }^{1}$ University of Wisconsin-Madison, Madison, WI, USA \\ ${ }^{2}$ Vilnius University, Vilnius, Lithuania \\ Email: egeorgian@gmail.com
}

Received 2 December 2015; accepted 25 January 2016; published 29 January 2016

Copyright (C) 2016 by authors and Scientific Research Publishing Inc.

This work is licensed under the Creative Commons Attribution International License (CC BY). http://creativecommons.org/licenses/by/4.0/

c) (†) Open Access

\section{Abstract}

This research investigated the interplay between nature and culture by focusing on knowledge about the genus Rhododendron in seven ethnic minorities (Bai, Dulong, Lisu, Naxi, Nu, Tibetan, and Yi) and the majority (Han) in Yunnan Province, China. Ethnobotanical uses of rhododendron were determined by interviewing 252 individuals. Using these data, we investigated patterns of knowledge distribution within each ethnic group and the majority to gain an understanding of who holds specific types of ethnobotanical knowledge. We conducted additional interviews with a subset of the interviewees to discuss their perception of knowledge loss and possible solutions. We find that every ethnic minority and the Han had uses for Rhododendron and that this knowledge is distributed unevenly within each ethnic group. Rhododendron knowledge is distributed by age, gender, or distance from tourist areas for use categories such as knowledge of songs, handicrafts, religious uses, and tourism. Additionally, 67.5\% of 84 interviewees believe that ethnobotanical knowledge is being lost.

\section{Keywords}

Rhododendron, Ethnobotany, Knowledge Distribution, Ethnic Minorities, Knowledge Loss

\section{Introduction}

Although every culture has ethnobotanical knowledge developed through frequent interactions with nature, in which plants have a deep cultural meaning [1] [2], this knowledge is often distributed throughout a population in specific patterns. For example, knowledge can be distributed within an ethnic group based on factors such as 
status, profession, age, gender, and location of their home (e.g., distance from a tourist destination or market etc.). A study among Mestizo communities in Venezuela's Caura Basin explored several factors that affected patterns of knowledge distribution, such as age, gender, and village origin [3] and showed that the amount of ethnobotanical knowledge that someone held depended on several factors at one time.

Patterns of knowledge distribution can also uncover cases of traditional ethnobotanical knowledge loss. For example, Zent (2001) described knowledge systems among the Piaroa in South America concluding that younger Piaroa held less ethnobotanical knowledge than older Piaroa [4]. Younger Piaroa have frequent contact with those outside their village and are more likely to attend school, which correlates with lower levels of ethnobotanical knowledge [4]. Other research shows that indigenous people are facing reductions in ethnobotanical knowledge due to factors such as increased access to foreign goods, distance from towns, restrictions on harvesting, gender, and age [5]-[8]. In Yunnan Province, China, a cultural diversity and biodiversity hotspot [9], ethnobotanical knowledge is declining due to rapid social change and acculturation, which is also a major factor that affects conservation of botanical diversity [10].

To study patterns of knowledge distribution and possible cases of ethnobotanical knowledge loss we first investigated the uses of rhododendron in northwest Yunnan Province, China. Yunnan Province is both a center of diversity of Rhododendron L. and a hotspot for cultural diversity with 25 ethnic groups, so it is unsurprising that a large body of ethnobotanical knowledge of rhododendrons exists in Yunnan [11] [12]. Much of this knowledge has not been previously recorded.

We aimed to record uses of rhododendron, determine if these uses were distributed, and investigate perceptions of loss of this knowledge among seven ethnic minorities (Bai, Dulong, Lisu, Naxi, Nu, Tibetan, and Yi) and the majority (Han). Patterns of knowledge distribution can uncover potential areas of ethnobotanical knowledge loss; therefore, investigating the perception of knowledge loss adds the people's own perspective to the discussion of traditional knowledge loss. Our research had the following three objectives: 1) To document uses of Rhododendron as described by seven different ethnic groups and the majority in northwest Yunnan Province, China. This complete investigation of Rhododendron uses not only reveals patterns in this knowledge, but also can be used as a baseline in future studies of cultural change. 2) To apply the interview data to elucidate patterns of knowledge distribution within each of the seven ethnic groups and the majority, and compare patterns of knowledge distribution among members of the seven ethnic minorities and the Han majority. 3) To investigate the perceptions of interviewees regarding ethnobotanical knowledge loss and their ideas for preventing this loss.

\section{Methods}

All interviews were conducted in northwest Yunnan Province in 2011 and 2012. Detailed field methods were previously described in Georgian and Emshwiller [11]. Interviews were conducted by E.G. who was proficient in spoken Mandarin Chinese and a trained field assistant to allow for comfort of the interviewee and any necessary translations from minority languages. The interviews were usually conducted in interviewees' homes or fields, except for Bai and Han interviews, which were mostly conducted in markets [11]. The interview protocol was qualified as exempt by the University of Wisconsin-Madison Social and Behavioral Sciences Review board as of June 2010. Ten Yes or No questions about uses of Rhododendron were asked of each interviewee $(\mathrm{N}=252)$ and those interviewees who answered Yes to a question were asked further questions relating to detailed knowledge of Rhododendron uses. Interviews were conducted with 30 Bai, 29 Dulong, 24 Han, 45 Lisu, 32 Naxi, 32 $\mathrm{Nu}, 29$ Tibetan, and $31 \mathrm{Yi}$.

A subset of the 252 interviewees $(\mathrm{N}=84)$ were asked questions about their perceptions of traditional cultural knowledge loss, specifically referring to whether knowledge about plants is being lost. Additionally, we asked these interviewees to suggest solutions to prevent and recover loss of knowledge. Each answer to the question "Is traditional cultural knowledge being lost?" was coded in a spreadsheet with Yes $=1$, Maybe $=0.5$, and No = 0 .

The data from all ten Yes or No interview questions were coded in a spreadsheet with Yes answers coded as 1, Maybe answers coded as 0.5 , and No or No-Response coded as 0 . Because information may be lost in the transformation of qualitative data to quantitative data we assessed a method of tallying our interview data. Other types of analyses may not accurately reflect the intricacies of our field-collected data because knowledge of a use $=1$, even though some interviewees knew more than one use for each category. For example, a Naxi traditional medicine doctor reported several uses for rhododendrons as medicine, which cannot be reflected in the 
count of $1=$ Yes, knowledge of uses in the category of medicine. This makes the knowledge that the Naxi traditional medicine doctor holds equal to a Naxi layman who knows of only one use of rhododendron for medicine. To remedy this inaccuracy we examined the interviews to count each use each person listed in each question category. Because many uses may have been listed in a category, it is possible for the tallied number of uses in each category to exceed the number of interviewees.

Counting multiple uses created weighted results, which allowed for a more accurate reflection of depth of knowledge our interviewees held. This data was then visually examined for trends of knowledge distribution in each ethnic group (Table 1). To determine distribution of knowledge based on age or gender we separated interviewees within each ethnic group into four categories: 1) females under 40 years old, 2) females over 40 years old, 3) males under 40 years old, and 4) males over 40 years old. We used 40 years old as our separation for ages because the average age of all interviewees $(N=252)$ was approximately 40 .

Splitting by gender and age decreased our sample size for each category; therefore, we suggest further studies to determine if our observed patterns hold with a larger sample size. We cannot generalize our data to all individuals within an ethnic group. The following descriptions of the eight ethnic groups are based on observations by E. Georgian during fieldwork (May 2010-August 2010, January 2011-August 2011, and February 2012-June 2012) in particular villages and thus are not representative throughout China, or even throughout Yunnan Province.

\section{Results and Discussion}

In the first section we report and discuss results for each ethnic group separately, based on the results of the tallying method (Table 1). This section is followed by discussion of a comparison of the patterns of knowledge distribution, and interviewees’ perception of ethnobotanical knowledge loss.

Table 1. Tallying method. It is possible for the tallied number of uses in each category to exceed the number of interviewees because people may know more than one use for each category.

\begin{tabular}{|c|c|c|c|c|c|c|c|c|c|c|c|}
\hline $\begin{array}{l}\text { Ethnic } \\
\text { Group }\end{array}$ & $\begin{array}{c}\text { \# of } \\
\text { Interviewees }\end{array}$ & Consume & Dye & Make & Medicine & $\begin{array}{l}\text { Stories, } \\
\text { Poems, } \\
\text { Saying }\end{array}$ & Songs & Incense & $\begin{array}{l}\text { Religion, } \\
\text { Festivals }\end{array}$ & $\begin{array}{c}\text { Horticulture/ } \\
\text { Decoration }\end{array}$ & Tourism \\
\hline Bai & 30 & & & & & & & & & & \\
\hline $\begin{array}{c}\text { Females } 40 \\
\text { and under }\end{array}$ & 15 & 7 & 0 & 2 & 2 & 2 & 1 & 0 & 0 & 4 & 7 \\
\hline $\begin{array}{l}\text { Females } \\
\text { over } 40\end{array}$ & 4 & 2 & 0 & 0 & 1 & 0 & 0 & 0 & 0 & 1 & 2.5 \\
\hline $\begin{array}{l}\text { Males } 40 \\
\text { and under }\end{array}$ & 8 & 8 & 0 & 2 & 0 & 2 & 1 & 0 & 0.5 & 2 & 3 \\
\hline $\begin{array}{c}\text { Males over } \\
40\end{array}$ & 3 & 1 & 0 & 1 & 1 & 0 & 0 & 0 & 0.5 & 0 & 0.5 \\
\hline Dulong & 29 & & & & & & & & & & \\
\hline $\begin{array}{c}\text { Females } 40 \\
\text { and under }\end{array}$ & 11 & 0 & 0 & 2 & 0 & 0 & 1 & 1 & 0 & 1.5 & 4 \\
\hline $\begin{array}{c}\text { Females } \\
\text { over } 40\end{array}$ & 2 & 0 & 0 & 0 & 0 & 0 & 0 & 0 & 0 & 0 & 1.5 \\
\hline $\begin{array}{l}\text { Males } 40 \\
\text { and under }\end{array}$ & 9 & 0 & 0 & 2 & 0 & 1 & 1 & 0 & 0 & 3 & 4.5 \\
\hline $\begin{array}{l}\text { Males over } \\
\quad 40\end{array}$ & 7 & 0 & 0 & 11 & 3 & 1 & 1 & 0 & 0 & 2 & 5 \\
\hline Han & 24 & & & & & & & & & & \\
\hline $\begin{array}{l}\text { Females } 40 \\
\text { and under }\end{array}$ & 6 & 1 & 0 & 1 & 0 & 0 & 1 & 0 & 1 & 1 & 2 \\
\hline $\begin{array}{c}\text { Females } \\
\text { over } 40\end{array}$ & 9 & 8 & 0 & 2 & 3 & 1 & 1 & 1 & 2 & 4 & 5 \\
\hline $\begin{array}{l}\text { Males } 40 \\
\text { and under }\end{array}$ & 5 & 1 & 0 & 2 & 1 & 0 & 1 & 0 & 0 & 1 & 3 \\
\hline
\end{tabular}




\section{Continued}

\begin{tabular}{|c|c|c|c|c|c|c|c|c|c|c|c|}
\hline $\begin{array}{c}\text { Males over } \\
40\end{array}$ & 4 & 2 & 0 & 0 & 2 & 0 & 0 & 0 & 1 & 3 & 2 \\
\hline Lisu & 45 & & & & & & & & & & \\
\hline $\begin{array}{c}\text { Females } 40 \\
\text { and under }\end{array}$ & 7 & 2 & 0 & 1 & 0 & 0 & 1 & 0 & 0 & 1 & 2 \\
\hline $\begin{array}{c}\text { Females } \\
\text { over } 40\end{array}$ & 5 & 0 & 0 & 0.5 & 1.5 & 2 & 0 & 0 & 1 & 1 & 0 \\
\hline $\begin{array}{l}\text { Males } 40 \\
\text { and under }\end{array}$ & 18 & 1 & 1 & 2 & 1 & 1 & 3 & 0 & 4 & 4 & 7 \\
\hline $\begin{array}{c}\text { Males over } \\
40\end{array}$ & 15 & 4 & 2 & 2.5 & 3.5 & 0 & 2 & 0 & 3 & 4 & 5 \\
\hline Naxi & 32 & & & & & & & & & & \\
\hline $\begin{array}{c}\text { Females } 40 \\
\text { and under }\end{array}$ & 1 & 0 & 0 & 2 & 0 & 0 & 1 & 0 & 0 & 1 & 1 \\
\hline $\begin{array}{c}\text { Females } \\
\text { over } 40\end{array}$ & 9 & 2 & 0 & 5 & 0 & 3 & 1 & 0 & 11 & 4 & 3 \\
\hline $\begin{array}{l}\text { Males } 40 \\
\text { and under }\end{array}$ & 3 & 1 & 0 & 2 & 0 & 0 & 0 & 0 & 4 & 1 & 2 \\
\hline $\begin{array}{c}\text { Males over } \\
40\end{array}$ & 19 & 11 & 0 & 19 & 6 & 0 & 2 & 0 & 15 & 17 & 17 \\
\hline $\mathrm{Nu}$ & 32 & & & & & & & & & & \\
\hline $\begin{array}{c}\text { Females } 40 \\
\text { and under }\end{array}$ & 9 & 0 & 0 & 4.5 & 2 & 2 & 2 & 1 & 1 & 1 & 3 \\
\hline $\begin{array}{c}\text { Females } \\
\text { over } 40\end{array}$ & 7 & 0 & 0 & 1 & 1 & 1 & 2 & 0 & 0 & 2 & 2 \\
\hline $\begin{array}{l}\text { Males } 40 \\
\text { and under }\end{array}$ & 9 & 2 & 0 & 1.5 & 3 & 0 & 3 & 0 & 1 & 3 & 2.5 \\
\hline $\begin{array}{c}\text { Males over } \\
40\end{array}$ & 7 & 1 & 2 & 3 & 4 & 1 & 0 & 0 & 1 & 1 & 3 \\
\hline Tibetan & 29 & & & & & & & & & & \\
\hline $\begin{array}{c}\text { Females } 40 \\
\text { and under }\end{array}$ & 7 & 1 & 0 & 5 & 1 & 1.5 & 3 & 1 & 0 & 1 & 5 \\
\hline $\begin{array}{c}\text { Females } \\
\text { over } 40\end{array}$ & 5 & 0 & 0 & 11.5 & 0 & 2 & 5 & 2 & 0 & 0 & 4 \\
\hline $\begin{array}{l}\text { Males } 40 \\
\text { and under }\end{array}$ & 6 & 1 & 0 & 13 & 2 & 0 & 1 & 1 & 2 & 0 & 5 \\
\hline $\begin{array}{c}\text { Males over } \\
40\end{array}$ & 11 & 0 & 0 & 27 & 0 & 2.5 & 4 & 1 & 2 & 1 & 8 \\
\hline $\mathrm{Yi}$ & 31 & & & & & & & & & & \\
\hline $\begin{array}{c}\text { Females } 40 \\
\text { and under }\end{array}$ & 5 & 5 & 1 & 8 & 1 & 1 & 4 & 0 & 6 & 1 & 5 \\
\hline $\begin{array}{c}\text { Females } \\
\text { over } 40\end{array}$ & 9 & 7 & 1 & 18 & 3 & 2 & 5 & 0 & 14 & 5 & 7 \\
\hline $\begin{array}{l}\text { Males } 40 \\
\text { and under }\end{array}$ & 9 & 8 & 0 & 17 & 4 & 3 & 6 & 0 & 8 & 4 & 8 \\
\hline $\begin{array}{c}\text { Males over } \\
40\end{array}$ & 8 & 8 & 2 & 10 & 3 & 2 & 2 & 0 & 12 & 0 & 4 \\
\hline
\end{tabular}




\subsection{Bai}

Bai is a major ethnic group in southwest China and consists of about 2 million people, with the majority living in Yunnan Province [13]. Bai people throughout southwest China are united by their language and Buddhist religion [13].

Rhododendron species are used for food by $43 \%$ of Bai interviewees in northwest Yunnan Province. Both female and male interviewees share the knowledge that rhododendron are used for food (Table 1). Bai people stated that they eat Rhododendron flowers ( $R$. decorum Franchet) because they taste good. Bai people collect the flowers themselves, or purchase rhododendrons from the markets in town, which were collected by others in nearby mountains. When purchasing fresh Rhododendron flowers the flowers are presented for sale soaked in water and the reproductive parts of the flower have previously been removed and discarded, leaving only the corolla (Figure 1(B)). The buyer tells the seller how many kilograms (6 RMB per KG in 2011) of Rhododendron corolla s/he would like to purchase and the seller picks up a bundle of corollas and squeezes out the water before weighing. In addition, preserved and packaged Rhododendron corollas, to be used when rhododendrons are not in flower, can be purchased at Bai markets in Dali Prefecture. Some restaurants in the Dali Old Town (a popular tourist destination; Dali Prefecture) sell these dishes to tourists as traditional Bai cuisine. Bai sellers recommend soaking the Rhododendron corollas for two to three more days after purchase, changing the water twice daily to remove toxins. Many species of Rhododendron contain grayanotoxins, a toxin that in small doses causes dizziness and in large doses can cause cardiac problems [14]. Examples of toxicity are known from Turkey as mad honey disease, where people were poisoned from eating honey tainted with grayanotoxins [15].

After elaborate processing, the Rhododendron corollas are deemed safe to eat and are cooked as a soup with flowers, beans, and salt, or as a broth to which broad-bean sauce is added. One Bai woman and three Bai men shared a recipe that described rhododendron corollas being cooked with beans and salted pork as a stir-fry. One Bai man also suggested that Rhododendron corollas could be pickled for later use. One Bai woman mentioned using Rhododendron honey, but noted that only certain Rhododendron spp. produce safe honey. Additionally, the flowers are simply cooked with eggs. Georgian observed Rhododendron flowers cooked with eggs, or combined with several other flowers in a soup offered at several restaurants in the Dali Old Town (Figure 1(C)).

The Bai people were described as having a 'flower eating culture,' but we found that only $43 \%$ of Bai interviewees said they ate rhododendrons [16] [17]. This may be due to the long-term integration of the Bai and Han (majority) as well as the rapid increase in tourism in Dali Prefecture [11] [12]. Tourism may decrease the use

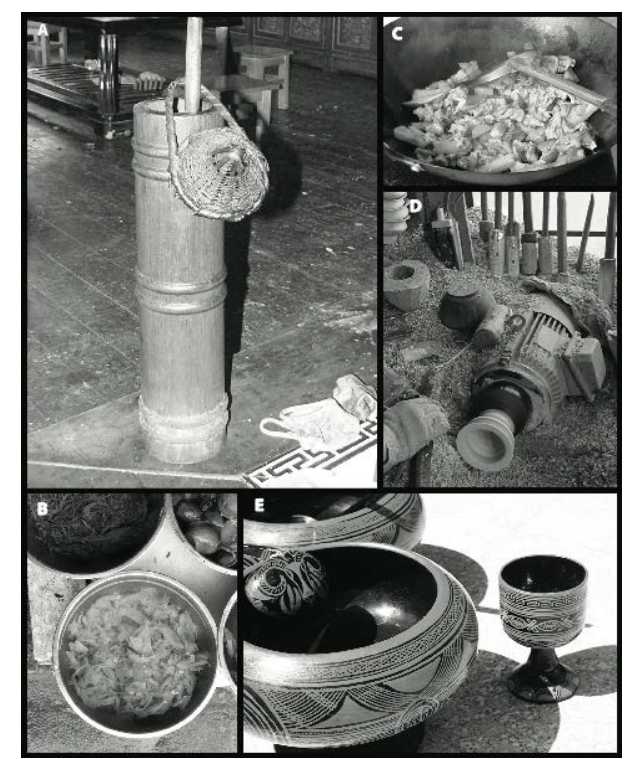

Figure 1. A compilation of images of material uses of rhododendrons. (A) a yak butter tea churner, (B) soaking Rhododendron corollas for consumption, (C) Rhododendron corollas cooked with potatoes, (D) Tibetan man carving a bowl made out of Rhododendron, (E) bowl, cup, and spoon made out of Rhododendron wood and painted in the Yi style. All photographs were taken by E. Georgian. 
of rhododendrons for food because people have more opportunities for jobs outside of the village, thus spend less time foraging for additional food in the mountains [18].

Rhododendron was thought to be important for tourism by $43 \%$ of Bai interviewees. More females (50\%) than males (31\%) thought that rhododendron were important for tourism. However this would need to be confirmed with further interviews, particularly of men, because we interviewed more Bai females $(\mathrm{N}=19)$ than males $(\mathrm{N}=11$; Table 1$)$.

\subsection{Dulong}

The Dulong ethnic minority is one of China's smallest minorities with approximately 4000 individuals [19]. The Dulong are found in Nujiang Prefecture, particularly in the rural Dulong River Valley region, which borders Myanmar [20]. The Dulong mainly practice subsistence agriculture and have some small opportunities for trade in Gongshan Town. Dulong women are known throughout China for their elaborate face tattooing, which is no longer practiced [21]. The Dulong traditionally practice forms of an animist religion [21].

Dulong interviewees rarely used rhododendron in any of the ten use categories [11]. Thirty-eight percent of Dulong interviewees mentioned using rhododendron wood to carve implements used in weaving (women weave a unique striped cloth) [21], saddles, plows, smoking pipes, and other household items. Among the Dulong, it was more common for males over 40 years of age to know of rhododendrons being used for making wood products than women or men under the age of 40 , and one man knew as many as three uses (Table 1 ). This could be because Dulong men typically go into the mountains where rhododendrons grow, while women stay near the home.

\subsection{Han}

Han people are the majority population of China making up about $91 \%$ of the population [13]. As Han is the majority group of China, we do not consider our data true for all Han throughout China. Our data and subsequent conclusions only refer to Han in a small area of Dali Prefecture.

Han people use rhododendron for consumption. Rhododendron is consumed as food by $33 \%$ of Han interviewees. The Han also process Rhododendron corollas similarly to the processing techniques of the Bai interviewees. Han interviewees said they use species with white corollas $(R$. decorum). Finally, the rhododendron corollas can be cooked with eggs and other flowers (Figure 1(C)), with salted pork and green beans, or made into a soup. One Han woman interviewee added that she boils Rhododendron flowers and adds them to cured meat. Another Han woman said that she cooks rhododendron in a soup, or stir-fry, or as a cold dish. Both of these Han women stated that they collected these flowers themselves from the mountain, and will occasionally sell them for six to seven RMB per $1 / 2 \mathrm{~kg}$. The tallying method indicates that Han women $(\mathrm{N}=6)$ know more about eating Rhododendron than their male counterparts ( $\mathrm{N}=3$; Table 1). Female interviewees also knew more than one recipe, while male interviewees knew only one recipe.

\subsection{Lisu}

The Lisu ethnic minority consists of approximately one million individuals with about 60\% living in China and 96\% of those in China living in Yunnan [22]. Lisu people live in northwest Yunnan Province, typically in Nujiang and Diqing Prefectures. Most Lisu people, particularly those living in Nujiang Prefecture, practice Christianity, which was introduced by French missionaries [23]. The Lisu language belongs to the Tibeto-Burman language family and is now a written language because of the creation of an alphabet by missionaries [22].

Lisu interviewees knew very few uses for Rhododendron species; however, some Lisu interviewees stated that they use Rhododendron for consumption, dyeing clothes, in religion, and in sayings. The sweet base of Rhododendron flowers ( $R$. floccigerum Franchet) is consumed as a sweet by $16 \%$ of Lisu interviewees. In addition to the use of Rhododendron nectar as a sweet, one Lisu man said that you could drink a tea made from Rhododendron; however, he said that it is not good to drink this tea in large quantities. Another Lisu man said that you could use the leaves of Rhododendron to wrap dough during cooking.

Lisu interviewees were one of the few ethnic minorities to describe Rhododendron used for dyeing purposes. Three interviewees (7\%) stated that in the past Rhododendron were used to make dyes for clothes, but are not used anymore because synthetic dyes can now be purchased in stores. 
Some (16\%) Lisu interviewees also described uses of Rhododendron in religion and festivals. In Christianity as practiced by Lisu interviewees in Nujiang Prefecture, individuals described picking Rhododendron flowers as decorations for church services. One Lisu man explained that Rhododendron is important in religion because it is 'arrogant and pure'. More male interviewees $(\mathrm{N}=7)$ described uses of rhododendron for religion than female interviewees ( $\mathrm{N}=1$; Table 1 ).

Regarding sayings, 7\% of Lisu interviewees were able to describe sayings referring to Rhododendron. If a Lisu girl is called a Rhododendron it means she is beautiful and this does not have a negative connotation (as it does in Naxi culture; $\mathrm{N}=1$ female). One female interviewee said that Lisu young men will try to put a Rhododendron flower on a young woman's clothes as a sort of love potion to make the young woman fall in love with them.

Twelve percent of Lisu interviewees shared songs about Rhododendron. Two male Lisu interviewees described a song about rhododendrons that equated people in love to looking like a beautiful Rhododendron flower. Another male interviewee recalled a communist party song that describes giving Rhododendron to party members.

\subsection{Naxi}

The Naxi people have a population of about 300,000 and primarily live in Lijiang Prefecture [24]. Many Naxi people have opportunities either first hand, or through their families to work in tourism due to Lijiang Old Town featuring the Naxi ethnic minority. Most Naxi people practice a religion called Dongba [25]. The Naxi minority has the last remaining pictographic writing system, which is primarily used by Dongba priests [24]. Naxi interviewees had significant knowledge about uses of Rhododendron, with 56\% of interviewees using Rhododendron for wood, $13 \%$ for medicine, $72 \%$ for religion, and $9 \%$ for stories songs and sayings.

Naxi interviewees said they use Rhododendron for their wood and woody roots for firewood and to make handicrafts. Naxi interviewees listed handicrafts made from Rhododendron wood such as bowls, large spoons, pipes, household carvings, plates, boxes, weaving shuttles, and saddles. Naxi males $(\mathrm{N}=12)$ compared to females $(\mathrm{N}=6)$ more frequently discussed using Rhododendron wood to make various items.

Naxi use rhododendrons for medicine. To protect the privacy of interviewees, specific details about Rhododendron for medicine will not be elaborated here. Naxi males over 40 years old $(\mathrm{N}=4)$ knew several uses of Rhododendron for medicine and the traditional medicine doctor $(\mathrm{N}=1)$ knew the most uses (three uses) and provided the most detailed knowledge. Only Naxi men knew the uses for medicine; however, few Naxi men in general knew medicinal uses for Rhododendron.

The Naxi have extensive intangible knowledge about Rhododendron. As described by interviewees $(\mathrm{N}=4)$, in the Naxi creation story Rhododendron was the first tree to grow after the great flood, and therefore is considered sacred. Additionally, interviewees stated that they, as well as Naxi religious specialists, use rhododendrons during ceremonies that take place on mountains $(\mathrm{N}=10)$. Naxi interviewees $(\mathrm{N}=8)$ stated that they burn leaves from Rhododendron species to expel spirits or ghosts from their homes. Two male Naxi Dongba religious specialists were interviewed. The younger specialist, a 35-year-old, knew four Rhododendron uses in religion, more than the two uses known by the 70-year-old specialist. Among non-specialists interviewed, men and women of wide age range knew a maximum of two Rhododendron uses in religion.

Naxi interviewees (9\%) recall stories, poems, and sayings that contrast the beauty of rhododendrons to its actual toxicity. Naxi interviewees associated the beauty and toxicity of rhododendrons with outer but not inner beauty of women. For example, if a Naxi girl is called a Rhododendron it means she is pretty on the outside but bad on the inside (because rhododendrons are toxic). A variation on this saying metaphorically equates rhododendrons with the short-lived beauty of women (encouraging women to be beautiful on the inside). Naxi women knew these sayings $(\mathrm{N}=3)$, while men had no knowledge of sayings.

A previously published Naxi story further describes the sayings that interviewees shared with E.G. [26]. Below we paraphrase a previously published Naxi story that describes a party that Rhododendron and several flowers and trees were invited to by the Flower Queen [26]. Rhododendron decided to come late to the party because she knew she was the most beautiful of all the flowers. Thus, despite her tardiness she would be awarded the seat beside the Flower Queen. Upon Rhododendron's arrival, she was surprised to find this prestigious seat was already occupied. This story highlighted the arrogance of Rhododendron and the importance inner beauty. 


\subsection{Nu}

The Nu ethnic minority consists of about 28,000 individuals who are mainly found in Nujiang Prefecture [27]. $\mathrm{Nu}$ people speak the Nu language, which is unwritten. The Nu practice their own indigenous religion and/or Christianity, which was introduced by French missionaries [23]. Nu interviewees described few uses of Rhododendron.

Only 6\% of Nu interviewees suggested that Rhododendron were used in festivals or religion. Previously recorded reports on the Nu ethnic group tell a story of a strong woman, named A-Rong who has been memorialized with a celebration involving rhododendrons. This story has been retold in several reports [28]-[32], which are summarized here. A-Rong was a major contributor to the organization of her community, and she invented a rope bridge to cross the Nujiang. Impressed with A-Rong's inventions, the head of the neighboring village planned to force A-Rong to be his bride. After learning of his intentions, A-Rong ran away from her village and hid in a Rhododendron forest. The man pursued her, and on March 15 burned the Rhododendron forest thus burning A-Rong alive. To honor A-Rong's bravery and intelligence, the Nu recognized A-Rong as a deity. Every year from March 15th through the 17th her memory is honored during the Flower (Fairy) Festival. At this festival Nu women gather Rhododendron flowers and offer them to the deity A-Rong as a sign of devotion and remembrance.

It should be noted that only two Nu and one Lisu interviewee discussed the Flower Festival. It is possible that the Flower Festival is a festival that takes place in only a specific location (Bingzhongluo, Gongshan), which was not covered sufficiently in the interviews. It is also possible that fewer people are practicing this festival due to the loss of cultural knowledge, which was likely impacted severely during the Cultural Revolution.

Tourism is increasingly becoming an important source of income for the people of Yunnan Province; however, only 34\% of $\mathrm{Nu}$ interviewees stated that Rhododendron are important for tourism. Nu people were interviewed in villages in Fugong County and Gongshan County of Nujiang Prefecture. Interviewees from Fugong County $(\mathrm{N}=24)$ stated that Rhododendron were not important for tourism $(\mathrm{N}=20)$ because rhododendrons are hard to view in that area and the roads are poor. Nu interviewees from Gongshan County $(\mathrm{N}=8)$ stated that Rhododendron are important for tourism $(\mathrm{N}=7)$ and go on to list specific places where Rhododendron are particularly important to tourism (e.g., Dimaluo and Bingzhongluo). Two Nu interviewees from Fugong County and one from Gongshan County did not know if rhododendrons were important for tourism (scored as 0 units). Interestingly, Gongshan County is north of Fugong County (there is only one road connecting Fugong County to Gongshan County) and therefore is more difficult to travel to and from; however, this does not seem to deter the small number of tourists it receives.

\subsection{Tibetan}

Tibetans make up a large ethnic group with a population of approximately 100,000 in Yunnan Province [23]. In Yunnan, the majority of Tibetans practice Tibetan Buddhism; however, some Tibetans living in Nujiang Prefecture practice Christianity. Many Tibetans living near Shangri-La have the opportunity for income through tourism, but they often also practice subsistence agriculture. Tibetans are spread over several provinces (e.g. Qinghai, Sichuan, Xizang, Yunnan), thus we cannot extrapolate our conclusions outside of northwest Yunnan Province.

Tibetan interviewees knew several uses for Rhododendron, especially regarding using woody parts of Rhododendron. Rhododendron is used as firewood and/or to carve household objects by 86\% of Tibetans ( $\mathrm{N}=25)$. Rhododendron wood and woody roots can be carved into utensils, bowls, yak butter tea churners, intricate household carvings, saddles, tsampa (toasted barley powder) containers, and numerous other small items (Figure 1(A)). Carved bowls (used as cups; Figure 1(D)) can be markers of specific statuses within the Tibetan community. For example, there are different bowls for use by monks, other adult males, women and children. Based on the tallying method, males $(\mathrm{N}=16)$ know more about uses of rhododendron for wood than females $(\mathrm{N}$ = 9; Table 1).

Rhododendron is used by $7 \%$ of Tibetans for religious purposes. In Christianity as practiced by some Tibetan interviewees in Nujiang Prefecture, individuals pick Rhododendron flowers as decorations for church services $(\mathrm{N}=2)$ and two Tibetans from Deqin Prefecture said they use rhododendrons as a tribute. In contrast, interviewees said that Rhododendron is not used in Tibetan Buddhism ( $\mathrm{N}=14)$. In fact, offering of rhododendrons to the Buddha is considered taboo $(\mathrm{N}=4)$.

Few Tibetan interviewees recalled stories involving Rhododendron (21\%). Young (both approximately age 25; 
$\mathrm{N}=2$ ), Tibetan interviewees remembered stories that take place at the Potala Nature Preserve near Shangri-La, Diqing Prefecture. These stories say that when Rhododendron petals fall into the lake the fish become temporarily poisoned. However, bears immune to the poison, come to the lake to take advantage of the immobilized fish.

Tibetan interviewees knew songs about Rhododendron (41\%). Some Tibetan songs refer to Rhododendron as the most beautiful flower and about Rhododendron and other flowers competing with each other in beauty. Three Tibetan men described a song about Rhododendron that says that it is the ugliest flower because it cannot be offered to Buddha. Another man knew a song about Rhododendron that explained when Rhododendron are open they are pretty but should not be put in a vase in your home. The average age of interviewees who knew songs about rhododendrons was 55.6 years of age, with the youngest at about 45 years of age. Our data shows that in the survey area, songs about Rhododendron are held by older Tibetan interviewees.

\subsection{Yi}

The Yi ethnic minority is one of China's largest ethnic minorities with approximately seven million people [23], and the majority of the population resides in Yunnan Province [33] [34]. The Yi people are classified into six different subgroups based upon the (not mutually comprehensible) dialect of Yi they speak [35]. For this research we primarily interviewed the Nuosu Yi people. Most Yi people practice their own indigenous religion and have two religious specialists, the bimo and the sunyi [36] [37]. One Yi bimo (a male religious leader) was interviewed. He was the only Yi interviewee who knew uses for Rhododendron in each of the ten use categories.

Ninety percent of Yi interviewees stated that they consume Rhododendron; however, their improved economic situation has decreased the use of rhododendrons for food. To prepare Rhododendron for consumption after collection, Yi interviewees shared that edible Rhododendron corollas must be put into boiling water. After boiling, the Rhododendron corollas must be put into fresh cold water for two to three days. After this processing they are deemed safe to eat. While most Yi did not describe recipes for cooking processed Rhododendron, one Yi woman said she eats Rhododendron corollas with eggs. Additionally, Yi woman ( $=13)$ said that children like to eat the nectar out of the flowers as a sweet snack.

Seventy-four percent of Yi people utilize woody parts of Rhododendron for household objects. Yi people carve several types of Yi spoons (including a special spoon for preparing pigs' food), goblets, bowls (Figure $1(E))$, mortars and pestles, plows and a wooden symbol used in religious practices.

Few people in all of the eight ethnic groups interviewed rarely used Rhododendron for dyes. Four Yi interviewees mentioned that pink and red flowered rhododendrons could be used to dye cloth a red or pink color. Two of the four interviewees added that touching the flowers stains your hands. The other two interviewees stated that you must boil the red Rhododendron corollas to extract the color. One Yi interviewee also volunteered that rhododendron flowers can be embroidered onto traditional costumes.

Rhododendrons are used during festivals or religious practices by $77 \%$ of Yi interviewees. Like the Naxi, the Yi $(\mathrm{N}=11)$ also burn leaves to expel ghosts and spirits from their homes. When planting the Yi's staple crops of buckwheat and potatoes, rhododendrons are used to bless the land hoping for a good harvest $(\mathrm{N}=10)$. The blessing involves placing Rhododendron flowers with wine in the east corner of the field. Each morning the sun rises, bringing good blessings and a hearty crop. Two Yi males described that after hunting and catching a large animal (for example not a bird but a deer) the hunter must use Rhododendron leaves and offer this to the gods thanking them for the good hunt. An Yi shaman (bimo) said that he uses rhododendrons to cure eye problems in the elderly, which are caused by ghosts coming to hurt the family.

Additionally, 26\% of Yi interviewees knew stories and sayings, and 55\% of Yi interviewees knew songs about Rhododendron. An Yi interviewee recounted a saying that warns children against picking or accepting rhododendrons, because rhododendrons can attract spirits who will take the children's health away. One Yi interviewee mentioned that corn should not be planted near some species of Rhododendron. Two Yi women sang a song describing the beauty of the time of year that rhododendrons bloom, which encourages friends to visit. This song also has a dance and in the past people danced and sang this song together in the evenings, but this does not occur any more.

\section{Patterns of Knowledge Distribution}

Overall, patterns of knowledge distribution were found among all ethnic groups included in this study and the Han majority. These identified patterns of knowledge distribution were correlated with gender, age, or village 
location, but are different for each of the different ethnic groups and the Han.

We found several patterns correlated with gender. Based on the tallying method, more Han females knew about consuming rhododendron than Han males. Because food preparation is traditionally a woman's role [5], it is not surprising that we found that women hold rhododendron knowledge pertaining to these activities. Dulong and Naxi men knew more about using rhododendron for its woody parts compared to their female counterparts. As interviewees confirmed, men often go to the mountains and learn this knowledge while woman stay near the home. It is also typical for men to hold knowledge related to financially relevant topics [38]. Other gender-correlated knowledge distribution was found among the Bai (more females thought Rhododendron was important for tourism), the Lisu (more males knew about religion), and the Naxi (males knew about medicine, females knew sayings). This is in agreement with other studies [5] [38] that found patterns of knowledge distribution based on gender.

Our data also shows patterns of age-correlated knowledge distribution. Tibetans with the average age of 55.6 more frequently discussed songs about Rhododendron. Dulong men over the age of 40 more frequently described knowledge about using the woody parts of Rhododendron for making household items, whereas Han women over 40-years-old more frequently knew to eat Rhododendron corolla compared to men or women 40 and under. This agrees with the findings of Zent (2001) among the Piaroa in Venezuela, as younger people typically move to the city and do not hold as much knowledge of traditional songs as their elders [4]. Our interviewees confirmed this by stating that the composition of villages is changing due to young people (particularly young men) finding jobs in construction or tourism outside of the village.

Location of the interviewee's village also plays a role in knowledge distribution. This is evident with the beliefs about the importance of Rhododendron to tourism among the Nu ethnic minority. Previous studies from around the world provide evidence showing that cultural changes are occurring and are occurring faster for individuals living closer to market towns [4] [8] [39] [40]. Additionally, in Nepal, the presence of foreign tourists brings increased exposure to globalization, causing people to be concerned about cultural identity change [41]. Our research provides additional examples from the Nu ethnic minority in China. More interviews related to other types of knowledge should be conducted to determine whether the patterns are similar to those of knowledge of Rhododendron, or if different or stronger patterns are revealed.

\section{Biocultural Conservation Concerns}

Conservation or loss of ethnobotanical knowledge is correlated with conservation or loss of biodiversity [42] [43]. In Yunnan, social change is impacting local knowledge about plants, which has been identified as one of the major factors impacting conservation of biodiversity [10]. Studying, documenting, encouraging, and remembering cultural knowledge about biodiversity may help to protect the environment. Therefore, it is urgent to work towards preserving the traditional ecological knowledge of cultures in southwest China and the world.

Among our 252 interviewees we asked 84 of them additional questions about loss of traditional ecological knowledge. Of these 84 interviewees, $67.5 \%$ believed that knowledge was being lost (Table 2). The respondents with the highest percentages of answering Yes to "Is traditional ethnobotanical knowledge being lost (i.e. are young people not learning about plants and other culturally important things)?” were Yi (95\%), followed by the Dulong (86\%), and Tibetan (80\%; Table 2). Our analyses on patterns of knowledge distribution uncovered examples of potential knowledge loss among interviewees at 40 years of age and under. Tibetan interviewees with the average age of 55.6 years old more frequently knew songs related to rhododendron. Dulong men over the age of 40 knew about using rhododendron wood for carving household items. Additionally, Naxi males over the age of 40 knew uses of Rhododendron for medicine. Interviewees blamed this loss of knowledge on the fact that younger generations were moving into towns and cities to find jobs in tourism and construction.

Previous research with Tibetans in Shangri-La County found that interviewees acknowledged the loss of traditional medicinal knowledge, similarly to the interviewees in this study [44]. The prevalence of clinics and hospitals in Shangri-La, and the availability of prepared medicines has made the knowledge of medicinal plants redundant as it is unnecessary to treat ailments yourself (E. G. field notes) [44]. Similarly, in the current study, E. G. observed that the availability of commercial dyes, household goods, and in general, a better economic situation had decreased the reliance on plants by ethnicities living in Yunnan Province. In her study, Glover (2007) concluded that the commercialization of Tibetan medicine had caused people to feel like they had lost an abundance of medicinal knowledge (that they might never have had in the first place) because Tibetan Medicine was 
Table 2. Are young people forgetting the uses of plants or traditional knowledge?

\begin{tabular}{cccc}
\hline Ethnic Group & Number of People Asked & Average Age & \% of Yes Responses \\
\hline Bai & 4 & 32 & $50 \%$ \\
Dulong & 7 & 48 & $86 \%$ \\
Han & 4 & 55 & $25 \%$ \\
Lisu & 11 & 40 & $68 \%$ \\
Naxi & 18 & 50 & $61 \%$ \\
Nu & 6 & 50 & $75 \%$ \\
Tibetan & 15 & 49 & $80 \%$ \\
Yi & 19 & 43 & $95 \%$ \\
Total & 84 & 46 & $67.5 \%$ \\
\hline
\end{tabular}

acknowledged by the world [44]. In contrast, the Dulong, Nu, and Lisu ethnic minorities are likely not known to many in the Western World; however, they also share the sentiment that ethnobotanical knowledge is being lost.

To counteract the perceived threat of knowledge loss interviewees provided examples and solutions. They suggested spending time in the mountains and with families to learn from nature and from each other. They also suggested wearing traditional clothes and eating traditional foods as a way to keep their culture alive. Interviewees also proposed that by teaching their children either themselves or through government run schools, they could preserve important aspects of their culture such as knowledge of useful plants. Preventing ethnobotanical knowledge loss is important for botanical conservation and it is encouraging that interviewees agreed with this sentiment.

\section{Acknowledgements}

E.G. thanks the interviewees for participation, graciously welcoming me into their homes, and becoming my dear friends. E.G. thanks the many field assistants involved, here kept anonymous, for their tireless work. This manuscript was improved by suggestions from colleagues and family members. This dissertation research was supported by grants to E.G. from the Botany Department at the University of Wisconsin-Madison, a Biodiversity Conservation and Sustainable Development in Southwest China NSF-IGERT traineeship (DGE\#0549369, an NSF GRFP fellowship, and a National Geographic Young Explorer Grant (9009-11).

\section{References}

[1] Berlin, B., Breedlove, D.E. and Raven, P.H. (1973) General Principles of Classification and Nomenclature in Folk Biology. American Anthropologist, 75, 214-242. http://dx.doi.org/10.1525/aa.1973.75.1.02a00140

[2] Zent, S. and Lopez Zent, E. (2004) Ethnobotanical Convergence, Divergence, and Change among the Hoti of the Venezuelan Guayana. In: Carlson, T.J.S. and Maffi, L., Eds., Ethnobotany and Conservation of Biocultural Diversity, Advances in Economic Botany Series, The New York Botanical Garden Press, Bronx, 9-35.

[3] Souto, T. and Ticktin, T. (2012) Understanding Interrelationships among Predictors (Age, Gender, and Origin) of Local Ecological Knowledge. Economic Botany, 66, 149-164. http://dx.doi.org/10.1007/s12231-012-9194-3

[4] Zent, S. (2001) Acculturation and Ethnobotanical Knowledge Loss among the Piaroa of Venezuela, a Demonstration of a Quantitative Method of the Empirical Study of Traditional Environmental Knowledge Change. In: Maffi, L., Ed., On Biocultural Diversity, Linkage Language, Knowledge, and the Environment, Smithsonian Institution Press, Washington DC, 190-211.

[5] Garibay-Orijel, R., Ramirez-Terrazo, A. and Ordaz-Velazquez, M. (2012) Women Care about Local Knowledge, Experiences from Ethnomycology. Journal of Ethnobiology and Ethnomedicine, 8, 25. http://dx.doi.org/10.1186/1746-4269-8-25

[6] Luczaj, L. (2008) Archival Data on Wild Food Plants Eaten in Poland in 1948. Journal of Ethnobiology and Ethnomedicine, 4, 4. http://dx.doi.org/10.1186/1746-4269-4-4

[7] Reyes-Garcia, V., Vadez, V., Huanca, T., Leonard, W. and McDade, T. (2007) Economic Development and Local 
Ecological Knowledge: A Deadlock? Quantitative Research from a Native Amazonian Society. Human Ecology, 35, 371-377. http://dx.doi.org/10.1007/s10745-006-9069-2

[8] Reyes-Garcia, V., Gueze, M., Luz, A.C., Paneque-Galvez, J., Macia, M.J., Orta-Martinez, M., Pino, J. and RubioCampillo, X. (2013) Evidence of Traditional Knowledge Loss among a Contemporary Indigenous Society. Evolution and Human Behavior, 34, 249-257. http://dx.doi.org/10.1016/j.evolhumbehav.2013.03.002

[9] Myers, N., Mittermeier, R.A., Mittermeier, C.G., da Fonesca, G.A. and Kent, J. (2000) Biodiversity Hotspots for Conservation Priorities. Nature, 403, 853-858. http://dx.doi.org/10.1038/35002501

[10] Ju, Y., Zhou, J.X., Liu, B. and Long, C.L. (2013) Eating from the Wild: Diversity of Wild Edible Plants Used by Tibetans in Shangri-La Region Yunnan, China. Journal of Ethnobiology and Ethnomedicine, 9, 28. http://dx.doi.org/10.1186/1746-4269-9-28

[11] Georgian, E. and Emshwiller, E. (2013) Shared and Separate Knowledge among Eight Cultural Groups Based on Ethnobotanical Uses of Rhododendron (Ericaceae) in Yunnan Province, China. Economic Botany, 67, 191-202. http://dx.doi.org/10.1007/s12231-013-9235-6

[12] Weckerle, C.S., Ineichen, R., Huber, F.K. and Yang, Y.P. (2009) Mao’s Heritage: Medicinal Plant Knowledge among Bai in Shaxi, China, at a Crossroads between Distinct Local and Common Widespread Practice. Journal of Ethnopharmacology, 123, 213-228. http://dx.doi.org/10.1016/j.jep.2009.03.014

[13] Staub, P.O., Geck, M.S. and Weckerle, C.S. (2011) Incense and Ritual Plant Use in Southwest China: A Case Study among the Bai in Shaxi. Journal of Ethnobiology and Ethnomedicine, 7, 43. http://dx.doi.org/10.1186/1746-4269-7-43

[14] Wong, J., Youde, E., Dickinson, B. and Hale, M. (2002) Report of the Rhododendron Feasibility Study. School of Agriculture and Forest Studies, University of Wales, Bangor.

[15] Koca, I. and Koca, A.F. (2007) Poisoning by Mad Honey: A Brief Review. Food and Chemical Toxicology, 45, 13151318. http://dx.doi.org/10.1016/j.fct.2007.04.006

[16] Pei, S.J. (1989) Traditional Culture of Flower Eating of Rhododendron and Bauhinia in Yunnan, China. Proceedings of the International Symposium on Flower-Eating Culture in Asia, Kunming, 1989.

[17] Pei, S.J. and Guo, H.J. (1989) Preliminary Study on Edible Flowers of northwest Yunnan. Asian Journal of Plant Sciences, 1, 69-77.

[18] Christanell, A., Vogyl-Lukasser, B., Vogl, C.R. and Gutler, M. (2010) The Cultural Significance of Wild-Gathered Plant Species in Kartitsch (Eastern Tyrol, Austria) and the Influence of Socioeconomic Changes on Local Gathering Practices. In: Pardo-de-Santayana, M., Pieroni, A. and Puri, R.K., Eds., Ethnobotany in the New Europe: People, Health and Wild Plant Resources, Berghahn Books, New York.

[19] Shen, S.C., Wilkes, A., Qian, J., Yin, L., Ren, J. and Zhang, F.D. (2010) Agrobiodiversity and Biocultural Heritage in the Dulong Valley, China. Mountain Research and Development, 30, 205-211. http://dx.doi.org/10.1659/MRD-JOURNAL-D-09-00085.1

[20] Gros, S. (2010) A Heuristic Blunder: Notes on an Ethnographic Situation in Southwest China. Asia Pacific Viewpoint, 51, 148-163. http://dx.doi.org/10.1111/j.1467-8373.2010.01421.x

[21] Luo, R.F. (1995) The Dulong, Face Tattooed Women in Nature. Yunnan Education Press, Kunming.

[22] Ji, H., Pei, S.J. and Long, C.L. (2004) An Ethnobotanical Study of Medicinal Plants Used by the Lisu People in Nujiang, Northwest Yunnan, China. Economic Botany, 58, s253-s264. http://dx.doi.org/10.1663/0013-0001(2004)58[s253:aesomp]2.0.c0;2

[23] Goodman, J. (2008) The Exploration of Yunnan. Yunnan People’s Publishing House, Kunming.

[24] Yang, L.X., Stepp, J.R., Ahmed, S., Pei, S.J. and Xue, D.Y. (2011) The Role of Montane Forests for Indigenous Dongba Papermaking in the Naxi Highlands of Northwest Yunnan, China. Mountain Research and Development, 31, 334-342. http://dx.doi.org/10.1659/MRD-JOURNAL-D-11-00035.1

[25] Pei, S.J., Hamilton, A.C., Yang, L.X., Huai, H.Y., Yang, Z.W., Gao, F. and Zhang, Z.X. (2010) Conservation and Development through Medicinal Plants: A Case Study from Ludian (Northwest Yunnan, China) and Presentation of a General Model. Biodiversity Conservation, 19, 2619-2636. http://dx.doi.org/10.1007/s10531-010-9862-5

[26] Han, C. (1997) Tales from within the Clouds: Nakhi Stories of China. University of Hawai’i Press, Honolulu.

[27] Tullos, D.D., Foster-Moore, E., Magee, D., Tilt, B., Wolf, A.T., Schmitt, E., Gassert, F. and Kibler, K. (2013) Biophysical, Socioeconomic, and Geopolitical Vulnerabilities to Hydropower Development on the Nu River, China. Ecology and Society, 18, 16. http://dx.doi.org/10.5751/ES-05465-180316

[28] All-China Women's Federation. Nu Ethnic Minority Fairy Festival. http://www.womenofchina.cn/Lifestyle/Customs/209756.jsp

[29] ChinaTravel.com. Nu Ethnic Minority. http://www.chinatravel.com/facts/nu-ethnic-minority.htm 
[30] Cultural China. The Fairy Festival of the Nu Ethnic Minority. http://traditions.cultural-china.com/en/115Traditions3986.htm

[31] Women of China. www.womenofchina.cn/

[32] Yang, F.S. (1999) The Mysterious Nujiang. A Series of Yunnan Scenery and Folklore Tourism. Yunnan Press, Yunnan.

[33] Harrell, S. (2001) Perspectives on the Yi of Southwest China. University of California Press, Berkeley. http://dx.doi.org/10.1525/california/9780520219885.001.0001

[34] Perrement, M. (2006) On the Margins: Migration among Miao, Yi and Tibetan People in China: A Special Report from China Development Brief. Case Study 3: Yi People in Sichuan. CBD Special Report.

[35] Bradley, D. (2001) Language Policy for the Yi. In: Harrell, S., Ed., Perspectives on the Yi of Southwest China, University of California Press, Berkeley, 195-213. http://dx.doi.org/10.1525/california/9780520219885.003.0013

[36] Ayi, B. (2001) On the Nature and Transmission of Bimo Knowledge in Liangshan. In: Harrell, S., Ed., Perspectives on the Yi of Southwest China, University of California Press, Berkeley, 118-132. http://dx.doi.org/10.1525/california/9780520219885.003.0009

[37] Grub, B.L. (2012) Culture, Ecology and Livestock Development in Two Nuosu Yi Villages in Liangshan, China. Dissertation, University of Washington, Seattle.

[38] Salick, J. and Moseley, R.K. (2012) Khawa Karpo: Tibetan Traditional Knowledge and Biodiversity Conservation. Missouri Botanical Gardens, St. Louis.

[39] de Grenade, R. and Nabhan, G.P. (2013) Agrobiodiversity in an Oasis Archipelago. Journal of Ethnobiology, 33, 203236. http://dx.doi.org/10.2993/0278-0771-33.2.203

[40] Scherrer, P. and Doohan, K. (2013) “It’s Not about Believing”: Exploring the Transformative Potential of Cultural Acknowledgement in an Indigenous Tourism Context. Asia Pacific Viewpoint, 54, 158-170. http://dx.doi.org/10.1111/apv.12016

[41] Adler, C.E., McEvoy, D., Chhetri, P. and Kruk, E. (2013) The Role of Tourism in a Changing Climate for Conservation and Development. A Problem Oriented Study in the Kailash Sacred Landscape, Nepal. Policy Sciences, 46, 161178. http://dx.doi.org/10.1007/s11077-012-9168-4

[42] Maffi, L. (2004) Maintaining and Restoring Biocultural Diversity: The Evolution of a Role for Ethnobiology. In: Carlson, T.J.S. and Maffi, L., Eds., Ethnobotany and Conservation of Biocultural Diversity, The New York Botanical Garden Press, Bronx, 9-35.

[43] Peacock, S.L. and Turner, N.J. (2000) "Just like a Garden”: Native Knowledge of Biodiversity in the Great Basin of Western North America. In: Minnis, P.E. and Elisens, W.J., Eds., Biodiversity and Native America, University of Oklahoma Press, Norman.

[44] Glover, D. (2007) The Land of Milk and Barley: Medicinal Plants, Staple Foods, and Discourses of Subjectivity in Rgyal Thang. In: Schremph, M., Ed., Soundings in Tibetan Medicine: Anthropological and Historical Perspectives, Brill, Leiden. 